\title{
Hypographs of Upper Semi-continuous Maps and Continuous Maps on a Bounded Open Interval
}

\author{
Nada Wu \\ Department of Mathematics and Statistics, Hanshan Normal University, Chaozhou, Guangdong, China \\ Email address: \\ 85157607@qq.com \\ To cite this article: \\ Nada Wu. Hypographs of Upper Semi-continuous Maps and Continuous Maps on a Bounded Open Interval. American Journal of Applied \\ Mathematics. Vol. 4, No. 2, 2016, pp. 75-79. doi: 10.11648/j.ajam.20160402.12
}

Received: February 3, 2016; Accepted: March 21, 2016; Published: March 25, 2016

\begin{abstract}
For any bounded open interval $X$ in the Euclidean space $E^{1}$, let $\downarrow U S C(X)$ and $\downarrow C(X)$ be the families of all hypographs of upper semi-continuous maps and continuous maps from $X$ to $I=[0,1]$, respectively. They are endowed with the topology induced by the Hausdorff metric of the metric space $\mathrm{Y} \times \mathrm{I}, \mathrm{Y}$ is the closure of $\mathrm{X}$. It was proved in other two papers respectively that $\downarrow \mathrm{USC}(\mathrm{X})$ and $\downarrow \mathrm{C}(\mathrm{X})$ are homeomorphic to $\mathrm{s}$ and $\mathrm{c}_{0}$ respectively, where $\mathrm{s}=(-1,1)^{\infty}$ and $\mathrm{c}_{0}=\left\{\left(\mathrm{x}_{\mathrm{n}}\right) \in(-1,1)^{\infty}\right.$ : $\left.\lim _{n \rightarrow \infty} X_{n}=0\right\}$. However the topological structure of the pair $(\downarrow U S C(X), \downarrow C(X))$ was not clear. In the present paper, it is proved in the strongly universal method that the pair of spaces $(\downarrow \operatorname{USC}(\mathrm{X}), \downarrow \mathrm{C}(\mathrm{X}))$ is pair homeomorphic to $\left(s^{\infty}, c_{0}^{\infty}\right)$ which is not homeomorphic to (s, $\left.\mathrm{c}_{0}\right)$. Hence this paper figures out the topological structure of the pair ( $\downarrow U S C(X), \downarrow C(X)$ ).
\end{abstract}

Keywords: Hypograph, Upper Semi-continuous Maps, Continuous Maps, Bounded Open Interval, Hausdorff Metric, The Property of Strongly Universal

\section{Introduction}

For a Tychonoff space $\mathrm{X}$ and a subspace $\mathrm{L}$ of the real line $\mathrm{R}$ with the usual topology, let $\mathrm{C}(\mathrm{X}, \mathrm{L})$ denote the set of all continuous maps from $\mathrm{X}$ to $\mathrm{L}$. $\mathrm{C}(\mathrm{X}, \mathrm{L})$ can be endowed with different topologies which are interesting for topologists. There are many research results in this field. In 1966 and 1991, two classical results were proved respectively which are listed below.

Theorem 1 [Anderson-Kadec Theorem] [1]. $\mathrm{C}_{\mathrm{u}}(\mathrm{X}, \mathrm{L})$ is homeomorphic to $(\approx)$ the Hilbert space $l_{2} \approx \mathrm{s}=(-1,1)^{\infty}[2]$ if $\mathrm{X}$ is an infinite compactum (a compactum means a compact metric space) and $\mathrm{L}=\mathrm{I}=[0,1]$ or $\mathrm{L}=\mathrm{R}$, where $\mathrm{C}_{\mathrm{u}}(\mathrm{X}, \mathrm{L})$ is $\mathrm{C}(\mathrm{X}, \mathrm{L})$ endowed with the uniformly convergence topology.

Theorem 2 [3]. $\mathrm{Cp}(\mathrm{X}, \mathrm{L}) \approx \mathrm{c}_{0}$ if $\mathrm{X}$ is a countable non-discrete metric space and $\mathrm{L}=\mathrm{R}$ or $\mathrm{L}=\mathrm{I}$, where $\mathrm{Cp}(\mathrm{X}, \mathrm{L})$ denotes $\mathrm{C}(\mathrm{X}, \mathrm{L})$ endowed with the pointwise convergence topology, and $\mathrm{c}_{0}=\left\{\left(\mathrm{x}_{\mathrm{n}}\right) \in(-1,1)^{\infty}: \lim _{\mathrm{n} \rightarrow \infty} \mathrm{x}_{\mathrm{n}}=0\right\}$.

In [4] to [7], $\mathrm{C}(\mathrm{X}, \mathrm{I})$ was endowed with another topology. To introduce this topology, it is necessary to recall the knowledge about hyperspace. For a metric space (M, d), the hyperspace $\mathrm{Cld}(\mathrm{M})$ is the set consisting of all non-empty closed subsets of $M$ endowed with Vietoris topology. Hausdorff distance $d_{H}$ defined as follows:

$$
\mathrm{d}_{\mathrm{H}}(\mathrm{A}, \mathrm{B})=\operatorname{Inf}\left\{\varepsilon: \mathrm{B}_{\mathrm{d}}(\mathrm{A}, \varepsilon) \supset \mathrm{B} \text { and } \mathrm{B}_{\mathrm{d}}(\mathrm{B}, \varepsilon) \supset \mathrm{A}\right\}
$$

for any $\mathrm{A}, \mathrm{B} \in \mathrm{Cld}(\mathrm{M})$. It is well-known that if $\mathrm{M}$ is compact, then $\mathrm{d}_{\mathrm{H}}$ is a metric and deduces Vietoris topology on Cld (M).

Let $\mathrm{X}$ be a space. A (single-valued) function $\mathrm{f}: \mathrm{X} \rightarrow \mathrm{R}$ is called upper semi-continuous if $f^{-1}(-\infty, t)$ is open in $X$ for every $\mathrm{t} \in \mathrm{R}$. For a Tychonoff space $\mathrm{X}$ and $\mathrm{L} \subset \mathrm{R}$, let $\mathrm{USC}(\mathrm{X}, \mathrm{L})$ denote the family of all upper semi-continuous maps from $\mathrm{X}$ to $\mathrm{L}$. For convenience, $\mathrm{USC}(\mathrm{X}, \mathrm{I})$ and $\mathrm{C}(\mathrm{X}, \mathrm{I})$ are abbreviated as $\mathrm{USC}(\mathrm{X})$ and $\mathrm{C}(\mathrm{X})$ respectively.

For every $\mathrm{f} \in \mathrm{USC}(\mathrm{X})$, let $\downarrow$ f be the region below of $\mathrm{f}$, that is, $\downarrow f=\{(\mathrm{x}, \lambda) \in \mathrm{X} \times \mathrm{I}: \lambda \leq \mathrm{f}(\mathrm{x})\}$ then $\downarrow \mathrm{f} \in \mathrm{Cld}(\mathrm{X} \times \mathrm{I})$.

Hence $\downarrow$ USC $(X)=\{\downarrow$ f: $\mathrm{f} \in \operatorname{USC}(\mathrm{X})\}$ and $\downarrow \mathrm{C}(\mathrm{X})=\{\downarrow \mathrm{f}: \mathrm{f} \in$ $\mathrm{C}(\mathrm{X})\}$ can be topologized as subspaces of the hyperspace $\mathrm{Cld}(\mathrm{X} \times \mathrm{I}) . \downarrow \mathrm{C}(\mathrm{X})$ can be considered as $\mathrm{C}(\mathrm{X})$ endowed with another topology which is different with the two former topologies ([4, Corollary 1]).

For two pairs of spaces $\left(\mathrm{X}_{1}, \mathrm{Y}_{1}\right)$ and $\left(\mathrm{X}_{2}, \mathrm{Y}_{2}\right)$ with $\mathrm{Y}_{1} \subset \mathrm{X}_{1}$ and $\mathrm{Y}_{2} \subset \mathrm{X}_{2}$, the symbol $\left(\mathrm{X}_{1}, \mathrm{Y}_{1}\right) \approx\left(\mathrm{X}_{2}, \mathrm{Y}_{2}\right)$ means that there exists a homeomorphism $h: X_{1} \rightarrow X_{2}$ such that $h\left(Y_{1}\right)=Y_{2}$. For a metric space $\mathrm{X}$, we use $\mathrm{X}_{0}$ and $\operatorname{cl}_{\mathrm{X}}(\cdot)$ to denote the set of all 
isolated points of $\mathrm{X}$ and the closure-operator in $\mathrm{X}$, respectively.

In 2005 , it was proved that $\downarrow \operatorname{USC}(X) \approx Q\left(Q=[-1,1]^{\infty}\right.$ is the Hilbert cube) when $\mathrm{X}$ is a compactum [8].

In 2006, there was the following result.

Theorem 3 [4]. For a Tychonoff space X, the following conditions are equivalent:

(a) $\mathrm{X}$ is a compactum and $\mathrm{cl}_{\mathrm{X}}\left(\mathrm{X}_{0}\right) \neq \mathrm{X}$;

(b) $\downarrow \mathrm{C}(\mathrm{X}) \approx \mathrm{c}_{0}$;

(c) $(\downarrow \mathrm{USC}(\mathrm{X}), \downarrow \mathrm{C}(\mathrm{X})) \approx\left(\mathrm{Q}, \mathrm{c}_{0}\right)$.

In 2009 , the following theorem was proved which indicated that the topological structure of $(\downarrow \mathrm{USC}(\mathrm{X}), \downarrow \mathrm{C}(\mathrm{X}))$ was figured out for every compactum $\mathrm{X}$.

Theorem 4 [7]. Let $\mathrm{X}$ be a compact metric space, $|\mathrm{X}|$ denotes the cardinal number of $X$, and $\Sigma=\left\{\left(x_{n}\right) \in Q\right.$ : $\sup \left\{x_{n}: n \in N^{+}\right\}<$ 1 ) be a subspace of Q, then

$$
\begin{aligned}
& (\downarrow \operatorname{USC}(\mathrm{X}), \downarrow \mathrm{C}(\mathrm{X})) \\
& \approx\left\{\begin{array}{cc}
\left(\mathrm{I}^{|X|}, \mathrm{I}^{|X|}\right) & \text { if } \mathrm{X} \text { is finite } \\
\left(\mathrm{Q}, \mathrm{c}_{0}\right) & \text { if } \mathrm{c} 1_{\mathrm{X}}\left(\mathrm{X}_{0}\right) \neq \mathrm{X} \\
\left(\mathrm{Q}, \mathrm{c}_{0} \cup(\mathrm{Q} \backslash \Sigma)\right) & \text { otherwises. }
\end{array}\right.
\end{aligned}
$$

If $\mathrm{X}$ is a non-compact space, $\downarrow \mathrm{USC}(\mathrm{X})$ and $\downarrow \mathrm{C}(\mathrm{X})$ can be endowed with Fell topology. From 2014 to 2016,Yang made a series of research in this area, see [9-11].

If $\mathrm{X}$ is a non-compact and topological complete metric space whose completion is compact, then $\downarrow$ USC(X) and $\downarrow \mathrm{C}(\mathrm{X})$ can be embed in $\downarrow$ USC(Y) as subspaces $[12,13]$, where $\mathrm{Y}$ is the completion of $X$. In fact, define a map $\downarrow$ : $\downarrow U S C(X) \rightarrow \downarrow U S C(Y)$ as following: for any $f \in U S C(X)$,

$$
e(f)(x)=\left\{\begin{array}{cc}
f(x) & x \in X \\
\lim _{y \rightarrow x, y \in X} f(y) & x \in Y \backslash X .
\end{array}\right.
$$

It had been proved in [12] that $\downarrow$ e is an isometric imbedding. In 2008 , there was the following result about $\downarrow \mathrm{USC}(\mathrm{X})$.

Theorem 5 [12]. $\downarrow \mathrm{USC}(\mathrm{X}) \approx l_{2} \approx \mathrm{S}$ if $(\mathrm{X}, \rho)$ is a non-compact and topological complete metric space whose completion is compact.

However, at that time, we didn't know the topological structure of $\downarrow \mathrm{C}(\mathrm{X})$ for every $\mathrm{X}$ satisfying the condition in Theorem 5. In 2013, we considered the case of $\mathrm{cl}_{\mathrm{X}}\left(\mathrm{X}_{0}\right) \neq \mathrm{X}$, and got the following result.

Theorem 6 [13]. If $\mathrm{X}$ is a noncompact, locally compact, totally bounded, separable metric space, then $\downarrow \mathrm{C}(\mathrm{X}, \mathrm{I}) \approx \mathrm{c}_{0}$ if and only if $\mathrm{cl}_{\mathrm{X}}\left(\mathrm{X}_{0}\right) \neq \mathrm{X}$.

We failed to prove that $(\downarrow \operatorname{USC}(\mathrm{X}, \mathrm{I}), \downarrow \mathrm{C}(\mathrm{X}, \mathrm{I})) \approx\left(\mathrm{s}, \mathrm{c}_{0}\right)$ for every noncompact, locally compact, totally bounded, separable metric space $\mathrm{X}$ with $\mathrm{cl}_{\mathrm{X}}\left(\mathrm{X}_{0}\right) \neq \mathrm{X}$. In this paper, we take a particular case, that is, consider $\mathrm{X}$ as a bounded open interval in the Euclidean space $\mathrm{E}^{1}$ and we prove the following main result.

Theorem 7. For any bounded open interval $\mathrm{X}$ in the Euclidean space $\mathrm{E}^{1},(\downarrow \mathrm{USC}(\mathrm{X}), \downarrow \mathrm{C}(\mathrm{X})) \approx\left(s^{\infty}, c_{0}^{\infty}\right)$.
Remark 1. In fact $\left(\mathrm{Q}^{\infty}, \mathrm{s}^{\infty}\right) \approx(\mathrm{Q}, \mathrm{s})$ and $\left(\mathrm{Q}^{\infty}, \mathrm{c}_{0}{ }^{\infty}\right) \approx\left(\mathrm{Q}, \mathrm{c}_{0}\right)$, however, $\left(\mathrm{s}^{\infty}, \mathrm{c}_{0}{ }^{\infty}\right)$ is not pair homemomorphic to $\left(\mathrm{s}, \mathrm{c}_{0}\right)$ [14]. Hence the above theorem indicates that $(\downarrow \operatorname{USC}(\mathrm{X}), \downarrow \mathrm{C}(\mathrm{X}))$ is not homeomorphic to $\left(\mathrm{s}, \mathrm{c}_{0}\right)$.

\section{Preliminaries}

All spaces under discussion are assumed to be separable metrizable spaces. All definitions on this section can be found in [15] or [16].

Definition 1 A space $\mathrm{X}$ is called an absolute retract, abbreviated AR, provided that for every space $\mathrm{Y}$ containing $\mathrm{X}$ as a closed subspace, $\mathrm{X}$ is a retract of $\mathrm{Y}$, that is, there exists a continuous map $\mathrm{r}: \mathrm{Y} \rightarrow \mathrm{X}$ such that $\mathrm{r}_{\mathrm{X}}=\mathrm{id}_{\mathrm{X}}$.

Definition 2 A closed subset $\mathrm{A}$ of a space $\mathrm{X}$ is said to be a Z-set of $\mathrm{X}$ if the identity $\mathrm{id}_{\mathrm{X}}$ can be approximated by continuous maps from $X$ to $X \backslash A$. A $Z \sigma$-set in a space is a countable union of Z-sets in the space. A space is called a $Z \sigma-$ space if it is a $Z \sigma-$ set of itself. We use $Z(X)$ and $Z \sigma(X)$ to denote the family of all Z-sets and the family of all $Z \sigma$-sets in $\mathrm{X}$, respectively. A Z-embedding is an embedding with a $\mathrm{Z}$-set image.

Definition 3 A subset A of a space $\mathrm{Y}$ is called homotopy dense in $\mathrm{Y}$ if there exists a homotopy $\mathrm{h}: \mathrm{Y} \times \mathrm{I} \rightarrow \mathrm{Y}$ such that $\mathrm{h}_{0}$ $=\mathrm{id}_{\mathrm{Y}}$ and $\mathrm{h}_{\mathrm{t}}(\mathrm{Y}) \subset \mathrm{A}$ for every $\mathrm{t}>0$.

Definition 4 Let $\mathrm{M}_{0}$ and $\mathrm{M}_{1}$ denote the class of compacta and the class of topological complete spaces, respectively. A space is called an absolute $\mathrm{F} \sigma$-space if it is an Fo-set in any space which contains it as a subspace. A space is called an absolute $\mathrm{F} \sigma \delta$-space if it is an $F \sigma \delta$-set in any space which contains it as a subspace. Let $\mathrm{M}_{2}$ denote the class of all absolute $F \sigma \delta$-spaces. Let $\left(\mathrm{M}_{0}, \mathrm{M}_{1}, \mathrm{M}_{2}\right)$ denote the class of all triples of spaces $(\mathrm{M}, \mathrm{B}, \mathrm{A})$ such that $\mathrm{M} \supset \mathrm{B} \supset \mathrm{A}, \mathrm{M} \in \mathrm{M}_{0}, \mathrm{~B} \in$ $\mathrm{M}_{1}$ and $\mathrm{A} \in \mathrm{M}_{2}$.

Definition 5 Let $\mathrm{F} \sigma$ denote the class of all absolute F $\sigma$-spaces. Let $(\mathrm{X}, \mathrm{d})$ be a copy of Hilbert cube $\mathrm{Q}$ and the pair of spaces $(X, Y) \in\left(M_{0}, M_{2}\right)$ (or res. $\left.\left(M_{0}, F \sigma\right)\right)$. We say that $(X$, $\mathrm{Y}$ ) is strongly $\left(\mathrm{M}_{0}, \mathrm{M}_{2}\right)$-universal (or res. strongly $\left(\mathrm{M}_{0}, \mathrm{~F} \sigma\right)$ universal)provided for $\operatorname{each}(\mathrm{M}, \mathrm{B}) \in\left(\mathrm{M}_{0}, \mathrm{M}_{2}\right)$ (or res. $\left(\mathrm{M}_{0}\right.$, Fo)), each continuous map $\mathrm{f}: \mathrm{M} \rightarrow \mathrm{X}$, each closed subset $\mathrm{K}$ of $M$ such that $\left.f\right|_{K}: K \rightarrow X$ is a Z-embedding and each $\varepsilon>0$, there is a Z-embedding $g: M \rightarrow X$ such that $\left.g\right|_{K}=\left.f\right|_{K}, g^{-1}(Y) \backslash K=$ $\mathrm{B} \backslash \mathrm{K}$ and $\mathrm{d}(\mathrm{g}(\mathrm{m}), \mathrm{f}(\mathrm{m}))<\varepsilon$ for each $\mathrm{m} \in \mathrm{M}$.

Remark 2. $\left(\mathrm{Q}^{\infty}, \mathrm{c}_{0}{ }^{\infty}\right)$ is strongly $\left(\mathrm{M}_{0}, \mathrm{M}_{2}\right)$-universal [14] and $(\mathrm{Q}, \Sigma)$ is strongly $\left(\mathrm{M}_{0}, \mathrm{~F} \sigma\right)$ universal [15].

Definition 6 Let $(\mathrm{X}, \mathrm{d})$ be a copy of Hilbert cube $\mathrm{Q}$ and the triple of spaces $(X, Y, Z) \in\left(M_{0}, M_{1}, M_{2}\right)$. We say that $(X, Y, Z)$ is strongly $\left(\mathrm{M}_{0}, \mathrm{M}_{1}, \mathrm{M}_{2}\right)$-universal provided for each

$(\mathrm{M}, \mathrm{B}, \mathrm{A}) \in\left(\mathrm{M}_{0}, \mathrm{M}_{1}, \mathrm{M}_{2}\right)$, each continuous map $\mathrm{f}: \mathrm{M} \rightarrow \mathrm{X}$, each closed subset $K$ of $M$ such that $\left.f\right|_{K}: K \rightarrow X$ is a $\mathrm{Z}$-embedding and each $\varepsilon>0$, there is a Z-embedding $\mathrm{g}: \mathrm{M} \rightarrow \mathrm{X}$ such that $\mathrm{g}|\mathrm{K}=\mathrm{f}| \mathrm{K}, \mathrm{g}^{-1}(\mathrm{Y}) \backslash \mathrm{K}=\mathrm{B} \backslash \mathrm{K}, \mathrm{g}^{-1}(\mathrm{Z}) \backslash \mathrm{K}$ $=\mathrm{A} \backslash \mathrm{K}$ and $\mathrm{d}(\mathrm{g}(\mathrm{m}), \mathrm{f}(\mathrm{m}))<\varepsilon$ for each $\mathrm{m} \in \mathrm{M}$.

Let $\Omega_{2}$ be the absorbing set in $\mathrm{R}^{\infty}$ for the class $\mathrm{M}_{2}$, constructed in [17].

The following lemma is a statement in [18, page 274].

Lemma 1. Let $\left(\mathrm{R}_{\mathrm{C}}{ }^{\infty}, \mathrm{R}^{\infty}, \mathrm{D}\right)$ be a triple of spaces with $\mathrm{D} \approx \Omega_{2}$, 
then $\left(\mathrm{R}_{\mathrm{C}}^{\infty}, \mathrm{R}^{\infty}, \mathrm{D}\right) \approx\left(\mathrm{R}_{\mathrm{C}}^{\infty}, \mathrm{R}^{\infty}, \Omega_{2}\right.$ (triple homeomorphism whose definition is similar as pair homeomorphism) if and only if $\left(\mathrm{R}_{\mathrm{C}}^{\infty}, \mathrm{R}^{\infty}, \mathrm{D}\right)$ is strongly $\left(\mathrm{M}_{0}, \mathrm{M}_{1}, \mathrm{M}_{2}\right)$-universal, $\mathrm{R}_{\mathrm{C}}=$ $[-\infty,+\infty]$.

Corollary 1. Let $(\mathrm{A}, \mathrm{B}, \mathrm{C})$ be a triple of spaces with $(\mathrm{A}, \mathrm{B}) \approx$ $(\mathrm{Q}, \mathrm{s})$ and $\mathrm{C} \approx \mathrm{c}_{0}$, then $(\mathrm{B}, \mathrm{C}) \approx\left(\mathrm{s}^{\infty}, \mathrm{c}_{0}{ }^{\infty}\right)$ if $(\mathrm{A}, \mathrm{B}, \mathrm{C})$ is strongly $\left(\mathrm{M}_{0}, \mathrm{M}_{1}, \mathrm{M}_{2}\right)$-universal.

Proof. Since $(\mathrm{A}, \mathrm{B}) \approx(\mathrm{Q}, \mathrm{s}) \approx\left(\mathrm{R}_{\mathrm{C}}^{\infty}, \mathrm{R}^{\infty}\right)$, there exists a homeomorphism $\mathrm{h}: \mathrm{A} \rightarrow \mathrm{R}_{\mathrm{C}}^{\infty}$ such that $\mathrm{h}[\mathrm{B}]=\mathrm{R}^{\infty}$. Put $\mathrm{D}=$ $\mathrm{h}[\mathrm{C}]$, then $(\mathrm{A}, \mathrm{B}, \mathrm{C}) \approx\left(\mathrm{R}_{\mathrm{C}}{ }^{\infty}, \mathrm{R}^{\infty}, \mathrm{D}\right)$ and $\mathrm{D} \approx \mathrm{c}_{0}$. If $(\mathrm{A}, \mathrm{B}, \mathrm{C})$ is strongly $\left(\mathrm{M}_{0}, \mathrm{M}_{1}, \mathrm{M}_{2}\right)$-universal then $\left(\mathrm{R}_{\mathrm{C}}^{\infty}, \mathrm{R}^{\infty}\right.$, D) is also strongly $\left(\mathrm{M}_{0}, \mathrm{M}_{1}, \mathrm{M}_{2}\right)$-universal. Note that $\Omega_{2} \approx \mathrm{c}_{0}{ }^{[17]},\left(\mathrm{R}_{\mathrm{C}}{ }^{\infty}, \mathrm{R}^{\infty}\right.$, $\mathrm{D}) \approx\left(\mathrm{R}_{\mathrm{C}}^{\infty}, \mathrm{R}^{\infty}, \Omega_{2}\right)$ by lemma 1 . Since $\left(\mathrm{R}^{\infty}, \Omega_{2}\right) \approx\left(\mathrm{s}^{\infty}, \mathrm{c}_{0}^{\infty}\right)[14]$, $(\mathrm{B}, \mathrm{C}) \approx\left(\mathrm{R}^{\infty}, \mathrm{D}\right) \approx\left(\mathrm{R}^{\infty}, \Omega_{2}\right) \approx\left(\mathrm{s}^{\infty}, \mathrm{c}_{0}^{\infty}\right)$.

\section{Proof of the Main Result}

In this section, $\mathrm{X}$ is always assumed for an bounded open interval in $\mathrm{E}^{1}$, and $\mathrm{Y}$ be the closure of $\mathrm{X}$ which is compact. We can define a metric $d$ on the product space $\mathrm{Y} \times \mathrm{I}$ as following,

$$
\mathrm{d}\left(\left(\mathrm{x}_{1}, \mathrm{t}_{1}\right),\left(\mathrm{x}_{2}, \mathrm{t}_{2}\right)\right)=\operatorname{Max}\left\{\left|\mathrm{x}_{1}-\mathrm{x}_{2}\right|,\left|\mathrm{t}_{1}-\mathrm{t}_{2}\right|\right\}
$$

for any $\left(\mathrm{x}_{1}, \mathrm{t}_{1}\right),\left(\mathrm{x}_{2}, \mathrm{t}_{2}\right) \in \mathrm{Y} \times \mathrm{I}$.

Let $\mathrm{d}_{\mathrm{H}}$ be the Hausdorff metric on $\mathrm{Cld}(\mathrm{Y} \times \mathrm{I})$.

\subsection{Some Lemmas for Proof of Theorem 3}

Lemma 2 [13, Corollary 3]. There exists homotopy $\mathrm{H}: \downarrow \mathrm{USC}(\mathrm{Y}) \times \mathrm{I} \rightarrow \downarrow \mathrm{USC}(\mathrm{Y})$ such that

$\mathrm{H}_{0}=\mathrm{id}_{\downarrow U S C(Y)}$, and $\mathrm{H}_{\mathrm{t}}(\downarrow U S C(\mathrm{Y})) \subset \downarrow \mathrm{C}(\mathrm{Y})$ for each $\mathrm{t}>0$, and $\mathrm{d}_{\mathrm{H}}(\mathrm{H}(\downarrow \mathrm{f}, \mathrm{t}), \downarrow \mathrm{f}) \leq \mathrm{t}$ for each $\mathrm{f} \in \mathrm{USC}(\mathrm{Y})$ and each $\mathrm{t} \in \mathrm{I}$.

Lemma 3 [5, Lemma 8]. Let A be a metric space and

$\mathrm{a}, \mathrm{b}: \mathrm{A} \rightarrow$ I two continuous maps with $\mathrm{a}(\mathrm{y})<\mathrm{b}(\mathrm{y})$ for each $\mathrm{y}$ $\in \mathrm{A}$. And let $\mathrm{M}: \mathrm{A} \times \mathrm{I} \rightarrow \mathrm{I}$ be a map satisfying the following conditions:

(1) for each fixed y0 $\in A, M(y 0, t): I \rightarrow I$ is increasing,

(2) for every fixed t $0 \in \mathrm{I}, \mathrm{M}(\mathrm{y}, \mathrm{t} 0): \mathrm{A} \rightarrow \mathrm{I}$ is continuous.

Then s: A $\rightarrow$ I defined by

$$
S(y)=\frac{1}{b(y)-a(y)} \int_{a(y)}^{b(y)} M(y, t) d t
$$

is continuous and $\mathrm{M}(\mathrm{y}, \mathrm{a}(\mathrm{y})) \leq \mathrm{s}(\mathrm{y}) \leq \mathrm{M}(\mathrm{y}, \mathrm{b}(\mathrm{y}))$ for every $\mathrm{y} \in \mathrm{A}$.

Lemma 4 [19, lemma 2.9]. $\left(\mathrm{Q}_{\mathrm{u}}, \mathrm{c}_{1}\right) \approx\left(\mathrm{Q}^{\infty}, \mathrm{c}_{0}{ }^{\infty}\right)$, where

$\mathrm{Q}_{\mathrm{u}}=[0,1]^{\infty}, \mathrm{c}_{1}=\left\{\left(\mathrm{x}_{\mathrm{n}}\right) \in \mathrm{Q}_{\mathrm{u}}: \lim _{\mathrm{n} \rightarrow \infty} \mathrm{x}_{\mathrm{n}}=1\right\}$.

Lemma 5 [15, Proposition 5.4.6]. (Q,Q $\backslash s) \approx(\mathrm{Q}, \Sigma)$.

Lemma 6 [4, Lemma 5]. Let $\mathrm{F}=\mathrm{E} \cup \mathrm{Z} \subset \downarrow \mathrm{USC}(\mathrm{Y})$ be closed.

If $\mathrm{Z}$ is a $\mathrm{Z}$-set in $\downarrow \mathrm{USC}(\mathrm{Y})$ and for every $\downarrow \mathrm{f} \in \mathrm{E}$ there exists a $\in \mathrm{Y}$ such that $\mathrm{f}(\mathrm{a})=0$, then $\mathrm{F}$ is a Z-set in $\downarrow \operatorname{USC}(\mathrm{Y})$.

\subsection{Proof of Theorem 3}

Since $(\downarrow U S C(Y), \downarrow U S C(X)) \approx(Q, s)[12], \downarrow C(X) \approx c_{0}[13]$, by Corollary 1 , it suffices to prove the following lemma.

Lemma 7. The triple of spaces ( $\downarrow$ USC(Y), $\downarrow \mathrm{USC}(\mathrm{X}), \downarrow \mathrm{C}(\mathrm{X})$ ) is strongly $\left(\mathrm{M}_{0}, \mathrm{M}_{1}, \mathrm{M}_{2}\right)$-universal.

Proof. Without loss of generality, assume that $\mathrm{X}=(-1,1)$,
$\mathrm{Y}=[-1,1]$. Let $\mathrm{x}_{\mathrm{n}}=1 / 2^{\mathrm{n}}, \mathrm{x}_{\mathrm{n}}^{\prime}=1 / 2^{\mathrm{n}}-1$ for every $\mathrm{n} \in \mathrm{N}^{+}, \mathrm{x}_{0}=$ 0 and $x_{\infty}=-1$, then $\lim _{n \rightarrow \infty} x_{n}=x_{0}$ and $\lim _{n \rightarrow \infty} x_{n}^{\prime}=x_{\infty}$. Let $(D$, $B, A)$ be a triple of spaces such that $(D, B, A) \in\left(M_{0}, M_{1}, M_{2}\right)$ and $\mathrm{K}$ be a closed subset of D. Let $\Phi: \mathrm{D} \rightarrow$ USC(Y) be a map such that $\downarrow \Phi: \mathrm{D} \rightarrow \downarrow U S C(Y)$ is continuous and $\left.\downarrow \Phi\right|_{\mathrm{K}}: \mathrm{K}$ $\rightarrow \downarrow U S C(Y)$ is a Z-embedding. By [7, Lemma 1.1], without loss of generality, we may assume that $\downarrow \Phi(K) \cap \downarrow \Phi(D \backslash K)=\varnothing$. For every $\varepsilon \in(0,1)$, let $\delta: Y \rightarrow[0,1)$ be a map defined by

$$
\delta(\mathrm{y})=(1 / 5) \min \left\{\varepsilon, \mathrm{d}_{\mathrm{H}}(\downarrow \Phi(\mathrm{y}), \downarrow \Phi(\mathrm{K}))\right\} .
$$

Then $\delta$ is continuous and $\delta(\mathrm{y})=0$ if and only if $\mathrm{y} \in \mathrm{K}$. For every $\mathrm{k} \in \mathrm{N}_{+}$, let

$$
\mathrm{D}_{\mathrm{k}}=\left\{\mathrm{y} \in \mathrm{Y}: 2^{-\mathrm{k}} \leq \delta(\mathrm{y}) \leq 2^{-\mathrm{k}+1}\right\} .
$$

Then $\bigcup_{k \in N}+D_{k}=D \backslash K$. In what follows, we shall define.

In what follows, we shall define $\Psi_{\mathrm{k}}: D_{\mathrm{k}} \rightarrow \mathrm{USC}(\mathrm{Y})$ for every $\mathrm{k} \in \mathrm{N}_{+}$, and then use these maps and $\left.\Phi\right|_{\mathrm{K}}$ to define a map $\Psi$ :D $\rightarrow \mathrm{USC}(\mathrm{X})$ such that $\downarrow \Psi: \mathrm{D} \rightarrow \downarrow U S C(Y)$ is a Z-embedding, $\left.\Psi\right|_{\mathrm{K}}=\left.\Phi\right|_{\mathrm{K}}, \Psi^{-1}(\mathrm{USC}(\mathrm{X})) \backslash \mathrm{K}=\mathrm{B} \backslash \mathrm{K}, \Psi^{-1}(\mathrm{C}(\mathrm{X})) \backslash \mathrm{K}=\mathrm{A} \backslash \mathrm{K}$ and $\mathrm{d}_{\mathrm{H}}$ $(\downarrow \Psi(\mathrm{y}), \downarrow \Phi(\mathrm{y}))<\varepsilon$ for each $\mathrm{y} \in \mathrm{D}$. This task will be finished in four steps.

It follows from Lemma 3, that there exists a homotopy $\mathrm{H}$ : $\downarrow \mathrm{USC}(\mathrm{Y}) \times \mathrm{I} \rightarrow \downarrow \mathrm{USC}(\mathrm{Y})$ such that

$\mathrm{H}_{0}=\mathrm{id}_{\downarrow U S C(Y)}, \mathrm{H}_{\mathrm{t}}(\downarrow U S C(\mathrm{Y})) \subset \downarrow \mathrm{C}(\mathrm{Y})$ and

$\mathrm{d}_{\mathrm{H}}\left(\mathrm{H}_{\mathrm{t}}(\downarrow \mathrm{f}), \downarrow \mathrm{f}\right) \leq \mathrm{t}$ for each $\mathrm{f} \in \mathrm{USC}(\mathrm{Y})$ and each $\mathrm{t} \in(0,1]$.

For each $\mathrm{y} \in \mathrm{D}$, and $\mathrm{t} \in \mathrm{I}$, let

$\downarrow \mathrm{h}(\mathrm{y})=\mathrm{H}(\downarrow \Phi(\mathrm{y}), \delta(\mathrm{y}))$,

$\mathrm{M}_{0}(\mathrm{y}, \mathrm{t})=\sup \left\{\mathrm{h}(\mathrm{y})(\mathrm{x}):\left|\mathrm{x}-\mathrm{x}_{0}\right|<\mathrm{t}\right\}$, and

$\mathrm{M}_{\infty}(\mathrm{y}, \mathrm{t})=\sup \left\{\mathrm{h}(\mathrm{y})(\mathrm{x}):\left|\mathrm{x}-\mathrm{x}_{\infty}\right|<\mathrm{t}\right\}$.

Then $\mathrm{h}(\mathrm{y}) \in \mathrm{C}(\mathrm{Y})$ for each $\mathrm{y} \in \mathrm{D} \backslash \mathrm{K}$ and

$\left.\downarrow h\right|_{D \backslash K}: D \backslash K \rightarrow \downarrow C(Y)$ is continuous.

Moreover, $\mathrm{d}_{\mathrm{H}}(\downarrow \mathrm{h}(\mathrm{y}), \downarrow \Phi(\mathrm{y})) \leq \delta(\mathrm{y})$ for every $\mathrm{y} \in \mathrm{D}$. It follows from the continuities of $\delta$ and $\mathrm{H}$ that

$\mathrm{M}_{0}, \mathrm{M}_{\infty}:(\mathrm{D} \backslash \mathrm{K}) \times \mathrm{I} \rightarrow \mathrm{I}$ satisfies the conditions (1) and (2) in Lemma 3.

Thus

$$
S_{i}(y)=\frac{1}{\delta(y)} \int_{\delta(y)}^{2 \delta(y)} M_{i}(y, t) d t(i=0 \text { oro })
$$

is continuous on $\mathrm{D} \backslash \mathrm{K}$ and $\mathrm{M}_{\mathrm{i}}(\mathrm{y}, \delta(\mathrm{y})) \leq \mathrm{s}_{\mathrm{i}}(\mathrm{y}) \leq \mathrm{Mi}(\mathrm{y}, 2 \delta(\mathrm{y}))$ for every $\mathrm{y} \in \mathrm{D} \backslash \mathrm{K}$.

By Definition 5 and Lemmas 4 and 5, there exist Z-embeddings $\alpha: \mathrm{D} \rightarrow \mathrm{Q}_{\mathrm{u}}$ and $\beta: \mathrm{D} \rightarrow \mathrm{Q}$ such that

$\alpha^{-1}\left[\mathrm{c}_{1}\right]=\mathrm{A}$ and $\beta^{-1}[\mathrm{Q} \backslash \Sigma]=\mathrm{B}$. If $\alpha(\mathrm{y})=\left(\mathrm{x}_{1}, \mathrm{x}_{2}, \cdots, \mathrm{x}_{\mathrm{n}}, \cdots\right)$ $\in \mathrm{Q}_{\mathrm{u}}$ and $\beta(\mathrm{y})=\left(\mathrm{z}_{1}, \mathrm{z}_{2}, \cdots, \mathrm{z}_{\mathrm{n}}, \cdots\right) \in \mathrm{Q}$, then the symbols $\alpha(\mathrm{y})(\mathrm{n})$ and $\beta(\mathrm{y})(\mathrm{n})$ denote $\mathrm{x}_{\mathrm{n}}$ and $\mathrm{z}_{\mathrm{n}}$, respectively. For each $\mathrm{n}$ $\in \mathrm{N}+$, define a map $\mathrm{V}_{\mathrm{n}}: \mathrm{D} \rightarrow \mathrm{I}$ by

$$
\mathrm{V}_{\mathrm{n}}(\mathrm{y})=\max \{|\beta(\mathrm{y})(\mathrm{i})|: \mathrm{i} \in\{1,2, \cdots, \mathrm{n}\}\}
$$

for every $y \in D$. It is easy to check that $V_{n}$ is continuous and $\lim _{\mathrm{n} \rightarrow \infty} \mathrm{V}_{\mathrm{n}}(\mathrm{y})=1$ if and only if $\mathrm{y} \in \mathrm{B}$.

Define continuous maps $\phi_{\mathrm{k}}: \mathrm{D}_{\mathrm{k}} \rightarrow \mathrm{I}$ by

$\phi_{\mathrm{k}}(\mathrm{y})=2-2^{\mathrm{k}} \delta(\mathrm{y})$. Since $\mathrm{y} \in \mathrm{D}_{\mathrm{k}}, 2^{-\mathrm{k}} \leq \delta(\mathrm{y}) \leq 2^{-\mathrm{k}+1}$. Hence $0 \leq \phi_{\mathrm{k}}(\mathrm{y}) \leq 1, \phi_{\mathrm{k}}(\mathrm{y})=0$ if $\delta(\mathrm{y})=2^{-\mathrm{k}+1}$ and $\phi_{\mathrm{k}}(\mathrm{y})=1$ if $\delta(\mathrm{y})=$ $2^{-\mathrm{k}}$. 
Let $\mathrm{Y}_{\mathrm{i}}=\left\{\mathrm{x} \in \mathrm{Y}: 2^{-\mathrm{i}-1} \leq\left|\mathrm{x}-\mathrm{x}_{0}\right| \leq 2^{-\mathrm{i}}\right\}$, and $\mathrm{Y}^{\prime}{ }_{\mathrm{i}}=\left\{\mathrm{x} \in \mathrm{Y}: 2^{-\mathrm{i}-1} \leq\left|\mathrm{x}-\mathrm{x}_{\infty}\right| \leq 2^{-\mathrm{i}}\right\}$, then $\mathrm{Y}=(1 / 2,1] \cup \cup_{\mathrm{i} \in \mathrm{N}+}\left(\mathrm{Y}_{\mathrm{i}} \cup \mathrm{Y}^{\prime}{ }_{\mathrm{i}}\right)$.

Define $\varphi_{\mathrm{i}}: \mathrm{Y}_{\mathrm{i}} \rightarrow \mathrm{I}$ by $\varphi_{\mathrm{i}}(\mathrm{x})=2^{\mathrm{i}+1}\left(2^{-\mathrm{i}}-\left|\mathrm{x}-\mathrm{x}_{0}\right|\right)$ for each $\mathrm{i} \in \mathrm{N}_{+}$. Then $\varphi_{\mathrm{i}}\left(\mathrm{x}_{\mathrm{i}}\right)=0$ and $\varphi_{\mathrm{i}}\left(\mathrm{x}_{\mathrm{i}+1}\right)=1$ for every $\mathrm{i} \geq 1$.

Define $\gamma_{\mathrm{i}}$ : $\mathrm{Y}^{\prime}{ }_{\mathrm{i}} \rightarrow \mathrm{I}$ by $\gamma_{\mathrm{i}}(\mathrm{x})=2^{\mathrm{i}+1}\left(2^{-\mathrm{i}}-\left|\mathrm{x}-\mathrm{x}_{\infty}\right|\right)$ for each $\mathrm{i} \in \mathrm{N}_{+}$. Then $\gamma_{\mathrm{i}}\left(\mathrm{x}_{\mathrm{i}}^{\prime}\right)=0$ and $\gamma_{\mathrm{i}}\left(\mathrm{x}_{\mathrm{i}+1}^{\prime}\right)=1$ for every $\mathrm{i} \geq 1$.

Step 2: For every $\mathrm{k} \in \mathrm{N}_{+}$, define a map $\Psi_{\mathrm{k}}$ on $\mathrm{D}_{\mathrm{k}}$.

For every $\mathrm{k} \in \mathrm{N}_{+}$, define a map $\Psi_{\mathrm{k}}: \mathrm{D}_{\mathrm{k}} \rightarrow \mathrm{USC}(\mathrm{Y})$ as follows:

for every $\mathrm{y} \in \mathrm{D}_{\mathrm{k}}$,

if $x \in(1 / 2,1] \cup \cup_{i \in\{1,2, \ldots, 2 k\}}\left(Y_{i} \cup Y^{\prime}{ }_{i}\right)$,

$\Psi_{\mathrm{k}}(\mathrm{y})(\mathrm{x})=\mathrm{h}(\mathrm{y})(\mathrm{x})$.

$\Psi_{\mathrm{k}}(\mathrm{y})\left(\mathrm{x}_{2 \mathrm{k}+1)}=\mathrm{h}(\mathrm{y})\left(\mathrm{x}_{2 \mathrm{k}+1}\right)\right.$;

$\Psi_{\mathrm{k}}(\mathrm{y})\left(\mathrm{x}_{2 \mathrm{k}+2}\right)=\left(1-\phi_{\mathrm{k}}(\mathrm{y})\right) \mathrm{s}_{0}(\mathrm{y})+\phi_{\mathrm{k}}(\mathrm{y}) \mathrm{h}(\mathrm{y})\left(\mathrm{x}_{2 \mathrm{k}+2}\right)$;

$\Psi_{\mathrm{k}}(\mathrm{y})\left(\mathrm{x}_{2 \mathrm{k}+3}\right)=\left(1-\phi_{\mathrm{k}}(\mathrm{y})\right) \delta(\mathrm{y})+\mathrm{h}(\mathrm{y})\left(\mathrm{x}_{2 \mathrm{k}+3}\right) \phi_{\mathrm{k}}(\mathrm{y})$;

$\Psi_{\mathrm{k}}(\mathrm{y})\left(\mathrm{x}_{2 \mathrm{k}+4}\right)=\mathrm{s}_{0}(\mathrm{y})$;

$\Psi_{\mathrm{k}}(\mathrm{y})\left(\mathrm{x}_{2 \mathrm{k}+5}\right)=\delta(\mathrm{y})$;

$\Psi_{\mathrm{k}}(\mathrm{y})\left(\mathrm{x}_{2 \mathrm{k}+6}\right)=\left(1-\phi_{\mathrm{k}}(\mathrm{y})\right) \delta(\mathrm{y}) \alpha(\mathrm{y})(1)+\phi_{\mathrm{k}}(\mathrm{y}) \mathrm{s}_{0}(\mathrm{y}) ;$

if $\mathrm{m}$ is odd and $\mathrm{m} \geq 7, \Psi_{\mathrm{k}}(\mathrm{y})\left(\mathrm{x}_{2 \mathrm{k}+\mathrm{m})}=\delta(\mathrm{y})\right.$;

if $\mathrm{m}$ is even and $\mathrm{m} \geq 8$,

$\Psi_{\mathrm{k}}(\mathrm{y})\left(\mathrm{x}_{2 \mathrm{k}+\mathrm{m}}\right)=\delta(\mathrm{y})\left[\left(1-\phi_{\mathrm{k}}(\mathrm{y})\right) \alpha(\mathrm{y})((\mathrm{m}+2) / 2-3)\right.$

$\left.+\phi_{\mathrm{k}}(\mathrm{y}) \alpha(\mathrm{y})(\mathrm{m} / 2-3)\right]$;

$\Psi_{\mathrm{k}}(\mathrm{y})\left(\mathrm{x}_{0}\right)=\delta(\mathrm{y})$;

if $x \in Y_{2 k+i}, i \in N_{+}$,

$\Psi_{\mathrm{k}}(\mathrm{y})(\mathrm{x})=\left(1-\varphi_{\mathrm{i}}(\mathrm{x})\right) \Psi_{\mathrm{k}}(\mathrm{y})\left(\mathrm{x}_{2 \mathrm{k}+\mathrm{i})}+\varphi_{\mathrm{i}}(\mathrm{x}) \Psi_{\mathrm{k}}(\mathrm{y})\left(\mathrm{x}_{2 \mathrm{k}+\mathrm{i}+1)}\right.\right.$.

$\Psi_{\mathrm{k}}(\mathrm{y})\left(\mathrm{x}^{\prime}{ }_{2 \mathrm{k}+1}\right)=\mathrm{h}(\mathrm{y})\left(\mathrm{x}^{\prime}{ }_{2 \mathrm{k}+1}\right)$;

$\Psi_{\mathrm{k}}(\mathrm{y})\left(\mathrm{x}^{\prime}{ }_{2 \mathrm{k}+2}\right)=\left(1-\phi_{\mathrm{k}}(\mathrm{y})\right) \mathrm{s}_{\infty}(\mathrm{y})+\phi_{\mathrm{k}}(\mathrm{y}) \mathrm{h}(\mathrm{y})\left(\mathrm{x}^{\prime}{ }_{2 \mathrm{k}+2}\right)$;

$\Psi_{\mathrm{k}}(\mathrm{y})\left(\mathrm{x}_{2 \mathrm{k}+3}^{\prime}\right)=\mathrm{h}(\mathrm{y})\left(\mathrm{x}_{2 \mathrm{k}+3}^{\prime}\right) \phi_{\mathrm{k}}(\mathrm{y})$;

$\Psi_{\mathrm{k}}(\mathrm{y})\left(\mathrm{x}_{2 \mathrm{k}+4}^{\prime}\right)=\mathrm{s}_{\infty}(\mathrm{y})$;

$\Psi_{\mathrm{k}}(\mathrm{y})\left(\mathrm{x}_{2 \mathrm{k}+5}^{\prime}\right)=0$;

$\Psi_{\mathrm{k}}(\mathrm{y})\left(\mathrm{x}^{\prime}{ }_{2 \mathrm{k}+6}\right)=\left(1-\phi_{\mathrm{k}}(\mathrm{y})\right) \delta(\mathrm{y}) \mathrm{V}_{1}(\mathrm{y})+\phi_{\mathrm{k}}(\mathrm{y}) \mathrm{s}_{\infty}(\mathrm{y}) ;$

if $\mathrm{m}$ is odd and $\mathrm{m} \geq 7, \Psi_{\mathrm{k}}(\mathrm{y})\left(\mathrm{x}^{\prime}{ }_{2 \mathrm{k}+\mathrm{m}}\right)=0$;

if $m$ is even and $m \geq 8$,

$\Psi_{\mathrm{k}}(\mathrm{y})\left(\mathrm{x}_{2 \mathrm{k}+\mathrm{m}}^{\prime}\right)=\delta(\mathrm{y})\left[\left(1-\phi_{\mathrm{k}}(\mathrm{y})\right) \mathrm{V}_{((\mathrm{m}+2) / 2-3)}(\mathrm{y})\right.$

$\left.+\phi_{\mathrm{k}}(\mathrm{y}) \mathrm{V}_{(\mathrm{m} / 2-3)}(\mathrm{y})\right]$;

$\Psi_{\mathrm{k}}(\mathrm{y})\left(\mathrm{x}_{\infty}\right)=\delta(\mathrm{y})$;

if $\mathrm{x} \in \mathrm{Y}^{\prime}{ }_{2 \mathrm{k}+\mathrm{i}}, \mathrm{i} \in \mathrm{N}_{+}$,

$\Psi_{\mathrm{k}}(\mathrm{y})(\mathrm{x})=\left(1-\gamma_{\mathrm{i}}(\mathrm{x})\right) \Psi_{\mathrm{k}}(\mathrm{y})\left(\mathrm{x}^{\prime}{ }_{2 \mathrm{k}+\mathrm{i}}\right)$

$+\gamma_{\mathrm{i}}(\mathrm{x}) \Psi_{\mathrm{k}}(\mathrm{y})\left(\mathrm{x}_{2 \mathrm{k}+\mathrm{i}+1}^{\prime}\right)$.

Step 3: Checking corresponding properties of maps $\Psi_{\mathrm{k}}{ }^{\prime} \mathrm{s}$ to prepare for defining the map $\Psi$.

Claim 1: For every $\mathrm{y} \in \mathrm{D}_{\mathrm{k}}, \Psi_{\mathrm{k}}(\mathrm{y})$ is well-defined on $\mathrm{Y}$, continuous on $\mathrm{Y} \backslash\left\{\mathrm{x}_{0}, \mathrm{x}_{\infty}\right\}$ and upper semi-continuous at $\mathrm{x}_{0}$ and $\mathrm{x}_{\infty}$. Moreover, $\lim _{\mathrm{x} \rightarrow \mathrm{x} \infty} \Psi_{\mathrm{k}}(\mathrm{y})(\mathrm{x})=\delta(\mathrm{y})=\Psi_{\mathrm{k}}(\mathrm{y})\left(\mathrm{x}_{\infty}\right)$ if and only if $\lim _{\mathrm{n} \rightarrow \infty} \mathrm{V}_{\mathrm{n}}(\mathrm{y})=1$ if and only if $\mathrm{y} \in \mathrm{B}$. Therefore, if $\mathrm{y} \in \mathrm{D}_{\mathrm{k}}$, then $\Psi_{\mathrm{k}}(\mathrm{y}) \in \mathrm{USC}(\mathrm{X})$ if and only if $\mathrm{y} \in \mathrm{B} \cap \mathrm{D}_{\mathrm{k}} . \Psi_{\mathrm{k}}(\mathrm{y})$ is continuous at $\mathrm{x}_{0}$ if and only if $\lim _{\mathrm{n} \rightarrow \infty} \alpha(\mathrm{y})(\mathrm{n})=1$ if and only if $\mathrm{y} \in \mathrm{A} \cap \mathrm{D}_{\mathrm{k}}$.

The proof of Claim 1 is trivial.

Claim 2: For each $\mathrm{k} \in \mathrm{N}_{+}, \quad \downarrow \Psi_{\mathrm{k}}: \mathrm{Y}_{\mathrm{k}} \rightarrow \downarrow \mathrm{USC}(\mathrm{Y})$ is continuous.

It can be proved like the proof of [4, Proposition 1].

Claim 3: $\Psi_{\mathrm{k}}(\mathrm{y})=\Psi_{\mathrm{k}+1}(\mathrm{y})$ for every $\mathrm{y} \in \mathrm{D}_{\mathrm{k}} \cap \mathrm{D}_{\mathrm{k}+1}$.

For every $\mathrm{y} \in \mathrm{D}_{\mathrm{k}} \cap \mathrm{D}_{\mathrm{k}+1}$, we have $\delta(\mathrm{y})=1 / 2^{\mathrm{k}}$.

Thus, $\phi_{\mathrm{k}}(\mathrm{y})=1$ and $\phi_{\mathrm{k}+1}(\mathrm{y})=0$.

If $x \in(1 / 2,1] \cup \cup_{i \in\{1,2, \ldots, 2 k\}}\left(Y_{i} \cup Y^{\prime}{ }_{i}\right)$,

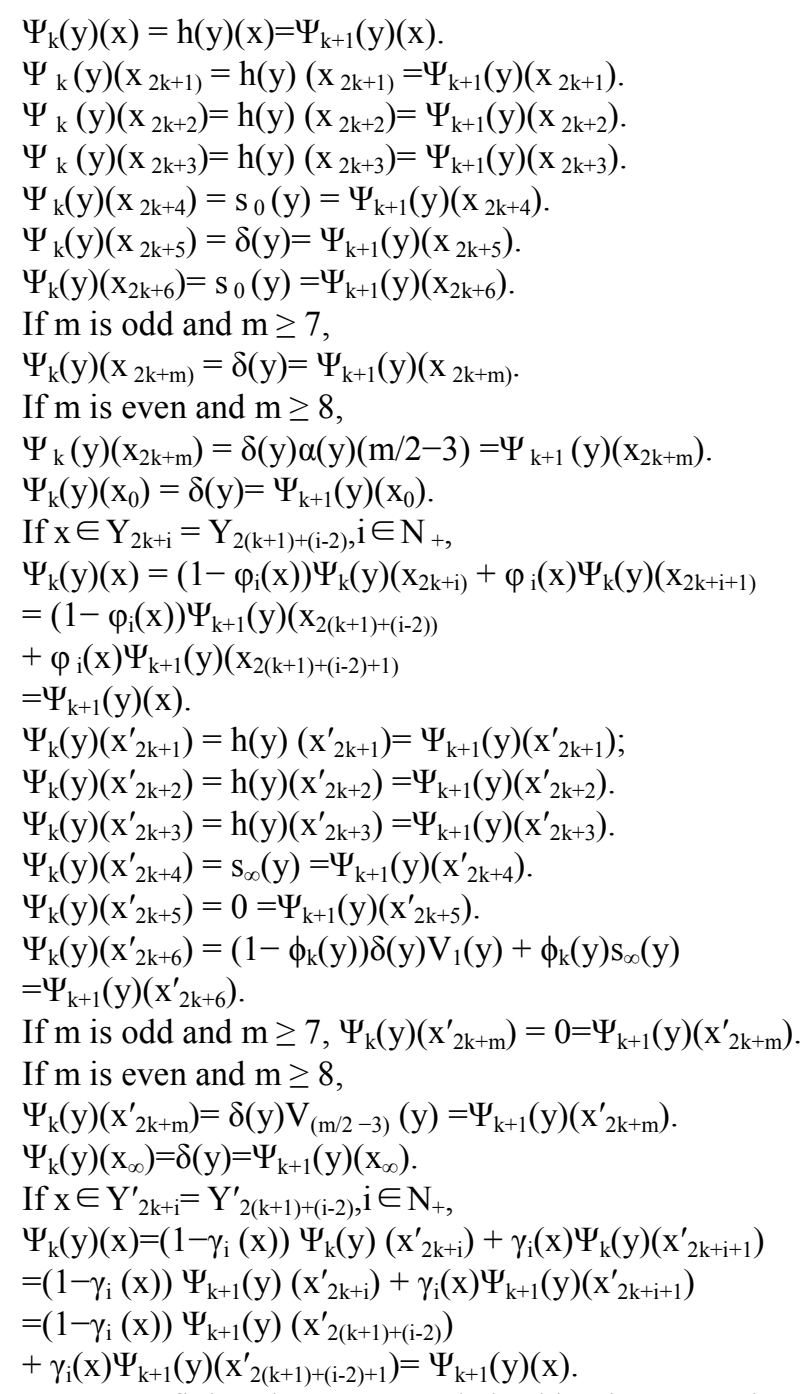

Step 4: Defining the map $\Psi$ and checking its properties Now we can define a map $\Psi: \mathrm{D} \rightarrow \mathrm{USC}(\mathrm{Y})$ as follows:

$$
\Psi(y)=\left\{\begin{array}{cc}
\Phi(y)=h(y) & y \in K \\
\Psi_{k}(y) & y \in D_{k}
\end{array}\right.
$$

Then $\left.\Psi\right|_{\mathrm{K}}=\left.\Phi\right|_{\mathrm{K}}$. Therefore, the following claims show that $\downarrow \Psi$ is as required.

Claim 4: For every y $\in \mathrm{D}, \mathrm{d}_{\mathrm{H}}(\downarrow \Psi(\mathrm{y}), \downarrow \Phi(\mathrm{y})) \leq 4 \delta(\mathrm{y})<\varepsilon$.

It can be proved similarly as the proof of [4, Proposition 1].

Claim 5: $\downarrow \Psi: \mathrm{D} \rightarrow \downarrow U S C(Y)$ is a Z-embedding.

Since D is compact, it suffices to prove the following three aspects.

(1). $\downarrow \Psi$ is continuous.

It follows from Claims 2, 3 and 4.

(2). $\Psi$ is an injection.

For any $\mathrm{y} 1, \mathrm{y} 2 \in \mathrm{D}$ with $\mathrm{y} 1 \neq \mathrm{y} 2$, we shall show $\Psi(\mathrm{y} 1) \neq$ $\Psi(\mathrm{y} 2)$. By the symmetry, we only consider the following three cases.

Case 1. $\mathrm{y} 1, \mathrm{y} 2 \in \mathrm{K}$. This fact is trivial.

Case 2. $\mathrm{y} 1 \in \mathrm{K}$ and $\mathrm{y} 2 \in \mathrm{D} \backslash \mathrm{K}$. Then, by Claim 4, $\mathrm{d}_{\mathrm{H}}(\downarrow \Psi(\mathrm{y} 2), \downarrow \Phi(\mathrm{y} 2)) \leq 4 \delta(\mathrm{y} 2)$.

On the other hand, it follows from the definition of $\delta$ that $\mathrm{d}_{\mathrm{H}}(\downarrow \Phi(\mathrm{y} 1), \downarrow \Phi(\mathrm{y} 2)) \geq \mathrm{d}_{\mathrm{H}}(\downarrow \Phi(\mathrm{K}), \downarrow \Phi(\mathrm{y} 2)) \geq 5 \delta(\mathrm{y} 2)>0$. 
We conclude that $\Psi(\mathrm{y} 1)=\Phi(\mathrm{y} 1) \neq \Psi(\mathrm{y} 2)$.

Case 3. $\mathrm{y} 1, \mathrm{y} 2 \in \mathrm{D} \backslash \mathrm{K}$. If $\Psi(\mathrm{y} 1)=\Psi(\mathrm{y} 2)$, then

$\delta(\mathrm{y} 1)=\Psi(\mathrm{y} 1)\left(\mathrm{x}_{\infty}\right)=\Psi(\mathrm{y} 2)\left(\mathrm{x}_{\infty}\right)=\delta(\mathrm{y} 2) \neq 0$. Thus there exists k such that $\mathrm{y} 1, \mathrm{y} 2 \in \mathrm{D}_{\mathrm{k}}$ and $\phi_{\mathrm{k}}(\mathrm{y} 1)=\phi_{\mathrm{k}}(\mathrm{y} 2)$.

On the other hand, for every $\mathrm{i} \in \mathrm{N}_{+}$,

$\Psi_{\mathrm{k}}(\mathrm{y} 1)\left(\mathrm{x}_{2 \mathrm{k}+\mathrm{i}}\right)=\Psi(\mathrm{y} 1)\left(\mathrm{x}_{2 \mathrm{k}+\mathrm{i}}\right)=\Psi(\mathrm{y} 2)\left(\mathrm{x}_{2 \mathrm{k}+\mathrm{i}}\right)=\Psi_{\mathrm{k}}(\mathrm{y} 2)\left(\mathrm{x}_{2 \mathrm{k}+\mathrm{i}}\right)$

Thus, if $\phi_{\mathrm{k}}(\mathrm{y} 1)=\phi_{\mathrm{k}}(\mathrm{y} 2)=1$, then $\alpha(\mathrm{y} 1)(\mathrm{m})=\alpha(\mathrm{y} 2)(\mathrm{m})$ for every $\mathrm{m} \in \mathrm{N}_{+}$by $\delta(\mathrm{y} 1)=\delta(\mathrm{y} 2)$ and the definition of $\Psi_{\mathrm{k}}(\mathrm{y} 1)\left(\mathrm{x}_{2 \mathrm{k}+\mathrm{i}}\right)$ and $\Psi_{\mathrm{k}}(\mathrm{y} 2)\left(\mathrm{x}_{2 \mathrm{k}+\mathrm{i}}\right)$ for every even number $\mathrm{i}$ with $\mathrm{i} \geq 8$. If $\phi(\mathrm{y} 1)$ $=\phi_{\mathrm{k}}(\mathrm{y} 2) \neq 1$, then $\alpha(\mathrm{y} 1)(\mathrm{m})=\alpha(\mathrm{y} 2)(\mathrm{m})$ for every $\mathrm{m} \in \mathrm{N}_{+}$by $\delta(\mathrm{y} 1)=\delta(\mathrm{y} 2)$ and the definition of $\Psi_{\mathrm{k}}(\mathrm{y} 1)\left(\mathrm{x}_{2 \mathrm{k}+\mathrm{i}}\right)$ and $\Psi_{\mathrm{k}}(\mathrm{y} 2)\left(\mathrm{x}_{2 \mathrm{k}+\mathrm{i}}\right)$ for every even number $\mathrm{i}$ with $\mathrm{i} \geq 4$. Thus $\alpha(\mathrm{y} 1)=$ $\alpha(y 2)$ in both cases. Since $\alpha: D \rightarrow Q_{u}$ is injective, we have that $\mathrm{y} 1=\mathrm{y} 2$ which contradicts with the assumption of $\mathrm{y} 1 \neq \mathrm{y} 2$.

(3). $\downarrow \Psi(D)$ is a Z-set of $\downarrow$ USC(Y).

$\downarrow \Psi(D)$ is compact by (1). Noticing that, for every $y \in D_{k}$, $\Psi(\mathrm{y})\left(\mathrm{x}_{2 \mathrm{k}+4}^{\prime}\right)=\Psi_{\mathrm{k}}(\mathrm{y})\left(\mathrm{x}_{2 \mathrm{k}+4}^{\prime}\right)=0$, it follows from Lemma 6 that $\downarrow \Psi(\mathrm{D})$ is a Z-set.

Claim 6: $\Psi^{-1}(\mathrm{USC}(\mathrm{X})) \backslash \mathrm{K}=\mathrm{B} \backslash \mathrm{K}$ and $\Psi^{-1}(\mathrm{C}(\mathrm{X})) \backslash \mathrm{K}=\mathrm{A} \backslash \mathrm{K}$.

In fact, for every $y \in D \backslash K$, there exists $k$ such that $y \in D_{k}$. It follows form the definition of $\Psi$ and Claim 1 . We are done.

\section{Conclusion}

For any bounded open interval $\mathrm{X}$ in the Euclidean space $\mathrm{E}^{1}$, $\downarrow \mathrm{USC}(\mathrm{X})$ is homeomorphic to $\mathrm{s}$ [12] and $\downarrow \mathrm{C}(\mathrm{X})$ is homeomorphic to $\mathrm{c}_{0}[13]$. However in this paper, it is proved that ( $\downarrow$ USC $(\mathrm{X}), \downarrow \mathrm{C}(\mathrm{X})$ ) is pair homeomorphic to the pair $\left(s^{\infty}, c_{0}^{\infty}\right)$ which is not pair homeomorphic to the pair $\left(\mathrm{s}, \mathrm{c}_{0}\right)$.

\section{Acknowledgements}

This work is supported by National Natural Science Foundation of China Youth Science Foundation Project (No. 11505042).

\section{References}

[1] R. D. Anderson, "Hilbert space is homeomorphic to countable infinite product of line," Bull. Amer. Math. Soc. vol.72, pp. 515-519.

[2] M. I. Kadec, "On topological equivalence of separable Banach spaces," Soviet Math. Dokl, vol. 7, pp. 319-322.

[3] T. Dobrowolski, W. Marciszewski, J. Mogilski, On topopogical classification of function spaces $\mathrm{Cp}(\mathrm{X})$ of low Borel complexity, Trans. Amer. Math. Soc., vol. 678, pp. 307-324.

[4] Z. Q. Yang, "The hyperspace of the regions below of continuous maps is homeomorphic to $\mathrm{c}_{0}$," Topology Appl., vol. 153, pp. 2908-2921.
[5] Z. Q. Yang, and X.E. Zhou, "A pair of spaces of upper semi-continuous maps and continuous maps," Topology Appl. vol. 154, pp. 1737-1747.

[6] Z. Q. Yang and N. D. Wu, "The hyperspace of the regions below of continuous maps from $\mathrm{S} \times \mathrm{S}$ to I, Questions and Answers in General Topology," vol. 26, pp. 29-39.

[7] Z. Q. Yang and N. D. Wu, "A topological position of the set of continuous maps in the set of upper semicontinuous maps," Sci. China, Ser. A, vol. 52, pp. 1815-1828.

[8] Z. Yang, "The hyperspace of the regions below of all lattice-value continuous maps and its Hilbert cube compactification," Sci. China Ser. A, vol. 48, pp. 469-484.

[9] Z. Q. Yang, and P. F. Yan, "Topological classification of function spaces with the Fell topology I," Topology Appl., vol. 178, pp. 146-159.

[10] Z. Q. Yang, Y. M. Zheng, and J. Y. Chen, "Topological classification of function spaces with the Fell topology II," Topology Appl., vol. 187, pp. 82-96.

[11] Z. Q. Yang, L. Z. Chen, and Y. M. Zheng, "Topological classification of function spaces with the Fell topology III," Topology Appl., vol. 197, pp. 112-132.

[12] Y. J. Zhang and Z. Q. Yang, "Hyperspaces of the Regions Below of Upper Semi-continuous Maps on Non-compact Metric Spaces," Advances in Mathematics (China), vol. 39, pp. 352-360.

[13] N. D. Wu, and Z. Q. Yang, "Spaces of Continuous Maps on a Class of Noncompact Metric Spaces," Advances in Mathematics (China), vol 42, pp. 535-541.

[14] R. Cauty, and T. Dobrowolski, "Applying coordinate products to the topological identification of normed spaces," Trans. Amer. Math. Soc., vol. 337, pp. 625-649.

[15] Van Mill J., The Infinite-Dimensional Topology of Function Spaces, Amsterdam: North-Holland Math. Library 64, Elsevier Sci. Publ. B. V., 2001.

[16] Van Mill J., Infinite-Dimensional Topology, Prerequisites and Introduction, Amsterdam: North-Holland Math. Library 43, Elsevier Sci. Publ. B. V., 1989.

[17] M. Bestvina, and J. Mogilski, "Characterizing certain incomplete infinite-dimensional absolute retracts," Michigan Math. J., vol. 33, pp. 291-313.

[18] R. Cauty, T. Dobrowolski and W. Marciszewski, "A contribution to the topological classification of the spaces $\mathrm{C}_{\mathrm{P}}(\mathrm{X})$ '. Fund. Math. vol. 142, pp. 269-301.

[19] Z. Q. Yang, S. R. Hu, and G. Wei, "Topological structures of the space of continuous functions on a non-compact space with the Fell Topology," Topology proceedings, vol. 41, pp. 17-38. 